\title{
A narrative review of esophageal tissue engineering and replacement: where are we?
}

\author{
Lynn Model $^{1} \wedge$, Ory Wiesel ${ }^{2}$ \\ ${ }^{1}$ Department of Pediatric Surgery, Maimonides Medical Center, Brooklyn, NY 11219, USA; ${ }^{2}$ Department of Thoracic Surgery, Maimonides Medical \\ Center, Brooklyn, NY 11219, USA \\ Contributions: (I) Conception and design: Both authors; (II) Administrative support: Maimonides Medical Center Department of Surgery; (III) \\ Provision of study materials or patients: None; (IV) Collection and assembly of data: None; (V) Data analysis and interpretation: None; (VI) \\ Manuscript writing: Both authors; (VII) Final approval of manuscript: Both authors. \\ Correspondence to: Lynn Model. Maimonides Medical Center, 984 50th St 3rd Flr, Brooklyn, NY 11219, USA. Email: 1model@maimonidesmed.org.
}

\begin{abstract}
Long-gap esophageal defects, whether congenital or acquired, are very difficult to manage. Any significant surgical peri-esophageal dissection that is performed to allow for potential stretching of two ends of a defect interrupts the esophageal blood supply and leads to complications such as leak and stricture, even in the youngest, healthiest patients. The term "congenital" applied to these defects refers mainly to long-gap esophageal atresia (LGA). Causes of acquired long-segment esophageal disruption include recurrent leaks and fistulae after primary repair, refractory GERD, caustic ingestions, cancer, and strictures. 5,000-10,000 patients per year in the US require esophageal replacement. Gastric, colonic, and jejunal pull-up surgeries are fraught with high rates of both short and long term complications thus creating a space for a better option. Since the 1970's many groups around the world have been unsuccessfully attempting esophageal replacement with tissue-engineered grafts in various animal models. But, recent advances in these models are now combining novel technologic advances in materials bioscience, stem-cell therapies, and transplantation and are showing increasing promise to human translational application. Transplantation has been heretofore unsuccessful, but given modern improvements in transplant microsurgery and immunosuppressive medications, pioneering trials in animal models are being undertaken now. These rapidly evolving medical innovations will be reviewed here.
\end{abstract}

Keywords: Esophagus; tissue engineering; esophageal atresia; esophageal replacement; esophageal transplantation

Submitted May 13, 2020. Accepted for publication Feb 10, 2021.

doi: 10.21037/atm-20-3906

View this article at: http://dx.doi.org/10.21037/atm-20-3906

\section{Introduction}

Five thousand to ten thousand patients per year in the US require esophageal replacement. In the pediatric population long-gap esophageal atresia (LGA) is the primary indication. LGA represents $10 \%$ of congenital tracheoesophageal fistulae which occur approximately $1 / 3,000$ births and the etiology is unknown. Some children with this condition will have success with a trial of waiting for spontaneous growth (12 weeks) or traction-induced growth
(Foker maneuver) with delayed primary repair, and some will not. Additional common indications for esophageal replacement in the pediatric population include recurrent leaks after primary repair of other types of esophageal atresia/tracheoesophageal fistula (EA/TEF), recurrent TEF after primary repair, refractory GERD, corrosive strictures, prolonged impaction of foreign bodies, and button battery erosions. Rarer indications include malignancies such as leiomyosarcoma and inflammatory pseudotumor,

\footnotetext{
$\wedge$ ORCID: 0000-0002-4555-1063.
} 
Table 1 Scaffold types, advantages and disadvantages

\begin{tabular}{|c|c|c|c|c|}
\hline Scaffold type & Absorbable? & Proven cell ingrowth? & Complications in animal models & Other notes \\
\hline PTFE and PET & No & Poor & Stricture, inflammation & \\
\hline PVDF & No & Good & Inflammation & \\
\hline Vicryl & Yes, 3 months & Moderate & Leak, disruption, inflammation & \\
\hline $\begin{array}{l}\text { PLA, PGA, PLLA, PLGA, } \\
\text { PCL }\end{array}$ & Yes, variable & Good & $\begin{array}{l}\text { Pseudodiverticula (in fast } \\
\text { absorbing polymers) }\end{array}$ & $\begin{array}{l}\text { Easier cell-seeding, } \\
\text { can 3D-print }\end{array}$ \\
\hline Decellularized ECMs & Yes & Good & Leak, stricture, stenosis & Release their own GFs \\
\hline SIS & Yes & Good & $\begin{array}{l}\text { Stricture, graft degradation, } \\
\text { inflammation }\end{array}$ & $\begin{array}{c}\text { Can be layered with polymer, } \\
\text { Easier cell-seeding }\end{array}$ \\
\hline
\end{tabular}

intractable achalasia, diffuse candidiasis in patients with immunodeficiency, scleroderma, epidermolysis bullosa and human immunodeficiency (HIV) related strictures (1).

Current options for esophageal replacement include stomach, jejunum and colon without any consensus as to which is the best option. This argument continues as all of these strategies are fraught with long and short term issues that include but are not limited to death, graft failure, leak, stricture, respiratory issues, dysphagia, reflux and dumping $(2,3)$. Allotransplant is not an ideal solution in children due to appropriate sized organ scarcity, rejection, and the potential lifetime of immunosuppression required, but is being explored potentially for adult use. The high-morbidity intestinal replacement procedures leave much to be desired, and thus enters the possibility of esophageal replacement with tissue-engineered grafts. Tissue engineering integrates material engineering with cellular biology and gene therapy to develop various tissue replacements that potentially have the same function as innate tissues. The components include the scaffold and the cells seeded onto it. Scaffolds and cell-seeding have been used for tissue replacement both together and separately depending on the extent of the injury. Heretofore most of these studies have been in animal models, but there is increasing promise to human translation (4).

Esophageal replacement has been tried in multiple iterations in the past 100 years. Unfortunately, due to the complexity of its replacement by both autologous and nonautologous organs, studies have been scarce and success has been limited.

In the following sections, we will explore the current knowledge on esophageal tissue engineering, reconstruction and transplantation.

We present the following article in accordance with the Narrative Review reporting checklist (available at http:// dx.doi.org/10.21037/atm-20-3906).

\section{Tissue engineering}

\section{Scaffolds (Table 1)}

Scaffolds provide a matrix for cell ingrowth and survival. Ideally they should be non-immunogenic, able to be formed into various sizes, and biodegradable such that they will eventually be replaced with host-cells or host-generated tissue (5).

Acellular scaffolds have been used with the idea that they will be populated with migration of host epithelial and smooth muscle cells. Types of acellular scaffolds include synthetic materials, collagen, and decellularized extracellular matrices (ECM). Early studies in the 1950s and $60 \mathrm{~s}$ with full-thickness esophageal replacement with plastic tubes or Marlex mesh demonstrated predictably very poor cellular ingrowth and thus poor results (leakage, stenosis, fistulae, dislocation) in animal models (6). Another early studied trialed polyethylene terephthalate (Dacron) and expanded polytetrafluoroethylene (PTFE) replacement of a full-thickness segment of canine esophagus. These materials generally had poor cell ingrowth with limited 
neoepithelialization and caused a significant foreign body reaction with fibrin formation and resultant stricture (7). Vicryl (polyglactin 910) mesh with a 3 -month average absorption time and non-absorbable polyvinylidene fluoride (PVDF) mesh were used in a 2004 study out of Germany with a full-thickness rabbit esophageal injury model. Vicryl mesh had a high rate of early leakage and failure with some evidence of limited re-epithelialization, some muscle cell ingrowth, and significant inflammatory reactions on histologic exam at 3 months. This is in contrast to the PVDF group which had no leaks and complete mucosal regeneration, some muscle cell ingrowth, and a small amount of foreign body reaction to the material. and did show evidence of neoangiogenesis as well (8). The omentum has been recognized to have a natural tendency to wall off perforations and contain infections, and thus has been used as a 'natural bioreactor' to aid in growth of implants of varying types. The implants in this study were wrapped in pedicalized omentum as a method of potentially decreasing leak and encouraging blood vessel ingrowth.

Collagen is the most prevalent ECM protein in the human body. Collagen has showed more promise than initial trials with older synthetics. A 1998 study from Japan replaced a $5 \mathrm{~cm}$ long segment of canine cervical esophagus with a double-layered tube of silicone interior stent and outer collagen sponge. Histological examination after silicone stent removal at 28 days with follow-up of 312 months demonstrated stratified epithelia with submucosal glands, inner circular and outer longitudinal muscle layers and no stenosis and no weight loss in the dogs (9). Longer cervical length $(10 \mathrm{~cm})$ and thoracic experimentation with the same model had a higher incidence of stenosis and less muscle ingrowth, even at 24 months. This is hypothesized by the authors to be due to less robust vascular supply in the thoracic esophagus as well as negative effects of pleural effusions after operation on the integrity of the collagen. In a further study by the same group, omental wrapping did not improve the outcomes of this scaffold in the thorax $(10,11)$.

There are many available biodegradable synthetic polymers that are showing promise as scaffolds in other organs such as the trachea. These include polyester-based aliphatic polymers such as polylactide (PLA), polyglycolide (PGA), poly(L-lactic acid) (PLLA), poly(lactic-coglycolic) acid (PLGA), and polycaprolactone/poly(Llactic acid) (PCL/PLLA). These polymers have shown positive epithelial cell-seeding capabilities resulting in stratified layers and keratinization (12). Adding collagen or fibronectin has been shown to improve cell adherence and function of esophageal epithelial cells, smooth muscle cells and fibroblasts on these scaffolds (13). PLA, PGA and PLGA are quite biodegradeable and biocompatible and have been approved by the FDA for other human applications. PGA degrades over 2-4 weeks, PLA over months to years, and PCL over years (14). PGA scaffolds seeded with smooth muscle cells, fibroblasts and keratinocytes have been used to replace segments of canine esophagus. This resulted in segments with histologically normal-appearing squamous epithelium and smooth muscle, but no peristalsis was present $(15,16)$. Poly- $\varepsilon$-caprolactone mesh was used to repair esophageal injuries in a rabbit study in 2015 with similarly-promising ingrowth of epithelial and smooth muscle cells at 30 days. These rabbits had a high incidence of pseudo-diverticula likely due to fast mesh degradation at this same time point of approximately 30 days (17).

Decellularized ECMs are a logical source of potential esophageal scaffold that provide three-dimensional microarchitecture of natural tissue and may promote cell growth without inducing inflammatory reactions that lead to graft stricture and leakage or failure. Collagen, elastin, fibronectin, laminin, and growth factors may be maintained on the ECM despite removal of the immunogenic cells that produced them (18). As the ECM is degraded by the host after implantation, there is further release of growth factors and peptides which influence angiogenesis, cell proliferation and differentiation, cell migration, and immune-cell infiltration (19). Sources include urinary bladder matrix (UBM), skin, pericardium, dura, gastric matrix, esophageal acellular matrix (EAM) and small intestinal submucosa (SIS). Decellularized scaffolds are prepared using mild detergents, acids, or enzymes to remove cells. Current methodologies for decellularization of different ECM sources often employ pressure controlled perfusion over multiple days and this strategy has been used in experiments for wholeorgan decellularization in the liver, uterus, penis, larynx, and skin/muscle flaps among others (20-22). Decellularized esophagus itself has also been described and utilized for esophageal replacement. Arakelian et al. describes in a 2019 study a method of esophageal decellularization using SDS and EDTA (23). A 2018 study by Luc et al. trialed such decellularized porcine esophagus to replace a full-thickness $5-\mathrm{cm}$ segment of pig esophagus, with and without cell seeding with human adipose-derived stem cells (hADSC) and with and without an intrabdominal omental maturation period. There were significant complications in $5 / 6$ pigs, though $5 / 6$ did survive to specimen harvest at 5 weeks and 
regained their previous weight as well. All specimen had 3 structural layers at the time of harvest. The omental maturation provided macroscopically visible neovascularization, but omental maturation was surgically detrimental in that these specimen were fibrous and difficult to anastomose. The hADSC seeding did not confer any significant beneficial change in graft cellularity or vascularization, postulated to be due to species incompatibility (24).

The same group that in 1999 trialed PTFE and Dacron segmental esophageal repairs also compared these to such an ECM, lyophilized dura mater (Lyodura). In contrast to the meshes, the esophagi in this group did have neoepithelialization at up to 12 month follow-up, but without significant smooth muscle cells noted, leading to more of a conduit rather than functional esophagus (7).

Alloderm (decelluarized human skin) has also been used in multiple experiments for partial esophageal replacement with mixed results. A 2001 study of 12 dogs with a $2 \mathrm{~cm} \times 1 \mathrm{~cm}$ alloderm esophagoplasty demonstrated neoepithelialization with neovascularization at 3 months with no leaks, strictures or diverticulae (25).

Small intestinal submucosa (SIS) has been used with poor results alone, but slightly better results when combined with other polymers and with cell-seeding techniques. A trial out of Germany in 2009 of replacement of $4 \mathrm{~cm}$ of piglet cervical esophagus with SIS alone resulted in 13/14 deaths by 4 weeks, mostly due to stricture and graft degradation (26). In a 2000 study by Badylak, $5 \mathrm{~cm} \mathrm{50 \%} \mathrm{defects} \mathrm{were} \mathrm{replaced} \mathrm{with}$ both SIS and urinary bladder submucosa (UBS) patches in a dog model. These demonstrated successful replacement by skeletal muscle and epithelium, but SIS and UBS graft tube repair of circumferential defects were plagued by strictures (27). Addition of synthetic polyesters such as PLGA and poly (3-hydroxybutyrate-co-3-hydroxyhexanoate) (PHBHHx) to SIS have been used in-vitro to improve the mechanical properties with some positive results but have not yet been trialed in animal models $(28,29)$. Cell-seeded SIS will be discussed in the next section.

Silk-Fibroin (SF) is another material that has been recently trialed for esophageal grafting with promising early results. These matrices are derived from silkworm cocoons, are biodegradable, and have low immunogenicity. A 2015 experiment with SIS versus SF in a rat esophageal injury model demonstrated superior muscle and nerve ingrowth in SF versus SIS as well as less inflammatory reaction and fibrosis in the SF group (30). In a subsequent investigation by the same group in a full-thickness injury $(3 \mathrm{~cm} \times 1.5 \mathrm{~cm})$ model in 6 pigs, grafts were implanted and then examined in 3 months. There were no leaks or strictures in any of the animals. Histologic exam revealed a stratified squamous epithelium, a muscularis mucosa and muscularis externa with circular and longitudinal layers, neovascularization and neuronal bundles (31). Preliminary experimentation with a multilayered poly( $\varepsilon$-caprolactone) and silk fibroin hybrid graft in a rat model of circumferential esophageal replacement demonstrated complete healing at 2 weeks in 8 out of 11 rats (32).

\section{Cell-seeding}

Cell-seeding is the transplantation of cultured cells, often from the patient themselves, either onto a scaffold and then to the site of injury or directly onto the injury. Many researchers have concluded that the most promise for a complete tissue-engineered esophageal replacement lies in a cell-seeded scaffold. Mesenchymal stem cells (MSCs) can be obtained from amniotic fluid, which may be of particular use in neonates with a prenatal diagnosis of EA. They act to release other factors such as TGF $\beta 1$, MCP1, VEGF and IL-6 that promote wound healing and modulate inflammation. MSCs are also present in bone marrow and adipose tissue. For the larger population in whom amniotic fluid MSCs are not applicable, esophageal epithelial cells (EECs) are a source of cells that can be obtained via endoscopy (33). Jensen et al. have recently experimented with amniotic MSCs and EECs seeded onto a polyurethane scaffold that gets extruded after tissue regeneration has occurred. The grafts were seeded, implanted into $5 \mathrm{~cm}$ defects in piglet esophagi, and the scaffolds extruded at 21 days. EEC seeding led to a complete stratified epithelium and one disorganized muscle layer by $4-5$ months while MSC seeding led to a complete stratified squamous epithelium and 2 distinct muscle layers after the same time period. The piglets did require stenting to support their esophagi during the healing time. The piglets had good growth over the study period and the new segments of esophagi (EEC and MSC) both propelled barium on esophagrams (33). Adipose-derived stem cells (ADSC) were utilized by the Luc group in seeding decellularized esophageal matricies. These cells secrete angiogenic factors and play an immune role. When cultured and seeded in sheets, both in in vitro and in vivo environments, no significant or satisfactory change in cellularization occurred. This was improved in non-sheet cultured ADSC when mucus membranes were removed to allow penetration into deeper submucosal and muscularis layers (24). 
In a canine model, oral mucosal epithelial cells (OMECs) have been harvested and cultured into 3-5 cell-thick layers and used to seed sites of injury created by large endoscopic submucosal dissections. The sheets were transported via an endoscope on a polyvinylidene difluoride (PVDF) membrane that was then removed after 10 minutes. Four week follow-up endoscopy revealed complete wound healing with no stenosis or fibrin, versus controls without cell-seeding that had fibrin, inflammatory cells, and central ulcers still remaining (34). In a similar experiment, OMECs were seeded onto SIS grafts (versus SIS alone) and used to replace a $50 \%$ circumferential $5-\mathrm{cm}$ defect in dogs. The OMECs group had faster neoepithelialization and muscular ingrowth with less inflammation versus the SIS alone group (35).

MSCs have also shown promise when seeded onto a SIS scaffold. In a 2013 experiment, a $5 \mathrm{~cm} \mathrm{50 \%} \mathrm{circumferential}$ defect was made in canine esophagi and replaced with either SIS alone or SIS seeded with bone marrow MSCs. The MSC group had more muscle ingrowth, neovascularization, epithelialization and less inflammation than the SIS group (36). A 2017 study out of France used MSCs seeded onto an SIS scaffold (versus SIS alone) to replace a $3 \mathrm{~cm}$ circumferential defect in pig esophagi. These scaffolds were matured on and implanted with an omental pedicle and around a removable stent. Histologic exam at 1-3 months demonstrated more epithelial and muscular cell ingrowth in the MSC group, though both groups had issues with stent migration and granulation tissue formation (37).

A recent study from the Mayo clinic utilized polyurethane scaffolds seeded with adipose-derived MSCs to replace a circumferential $6 \mathrm{~cm}$ defect in pigs, supported by an intraluminal stent and treated with platelet-rich plasma (PRP) and more MSCs at 3 weeks. At 3 months the grafts had a mature mucosal layer with underlying mesenchyme with smooth muscle cells in it. Two pigs with their stents removed at 6 months were still alive at 18 and 19 months at the time of publication and awaiting further analysis (38).

\section{Human experimentation}

Limited studies have been performed in humans using the various materials and methods described above. In 2011, a University of Pittsburgh group performed long-segment circumferential endoscopic resection of Barrett's esophagus down to the muscularis in 5 patients and the defects were covered with SIS held in place with a self-expanding stent. The stent was removed 9-18 days later, and endoscopic surveillance revealed degradation of the graft by 2 weeks and regeneration of the squamous epithelium as early as 4 months. There were multiple issues with post-operative strictures requiring dilations (39).

A Japanese group has successfully been using sheets of autologous oral mucosal epithelial cells applied to extensive areas of endoscopic submucosal dissection (ESD) in humans to reduce complications and speed re-epithelialization. In 9 patients, cell sheets of oral mucosa were cultured in-vitro for 16 days and transported on polyvinylidene difluoride support membranes to the ulcer sites with an endoscope. This procedure reduced average epithelial healing time from 4 to 3.5 weeks. One patient with a circumferential defect had a stricture requiring balloon dilation, and the other 8 had no evidence of stricture (40).

In a recent study from Argentina, 4 patients with large esophageal defects were repaired by tissue-engineered patches. Patches were created from 8-layered porcine urinary bladder matrix and sizes ranged from $4 \times 2 \mathrm{~cm}$ to $5 \times 3 \mathrm{~cm}$ and were sutured in place. There was one small contained leak and all patients had complete mucosal coverage at 2 months by EGD, with biopsy showing normal squamous epithelium (41).

A 24 year old with a large $(5 \mathrm{~cm})$ but not circumferential cervical esophageal defect underwent repair with alloderm covered in platelet-rich-plasma and a sternocleidomastoid muscle graft with internal self-expanding metal stent. After stent removal, EUS and biopsy demonstrated stratified epithelium, muscularis mucosa, submucosa, muscularis propria and adventitia in the repaired area with normal motility by manometry (42).

\section{$3 D$ printing}

Early studies in animals of the use of 3D printed scaffolds are starting to show promise. 3D printing allows fabrication in any shape from a digital image. A 2016 study from Park et al. utilized 3D printed esophageal scaffolds made from PCL and seeded with MSCs from rabbits, to repair a surgically created esophageal defect in these animals. All 6 subjects survived to harvest at 3 weeks and had no major complications. Mucosal epithelium and smooth muscle cells were seen in the specimen (43). Similarly Park et al. utilized a rat esophageal injury model to trial patches created with 3D printed PCL, seeded with ADSCs, as well as polyurethane-nanofiber (PU) scaffolds. They found 
that all defects were successfully repaired, but with better muscle regeneration in the PCL group, and better epithelial regeneration in the PU group (44). In 2018, Chung et al. used 3D-printed PCL with thicker reinforcing PCL rings and additional electrospun PCL to create circumferential esophageal scaffolds. These scaffolds were then cultured in vivo in rat omentum and subsequently used as interposition grafts for full-thickness circumferential esophageal defects. All rats (10) died up to 2 weeks after graft orthotopic transplantation (the time of death sacrifice) due to stenosis with obstruction by hair ingestion leading to malnutrition and proximal anastomotic leak. At the time of death/sacrifice they did have epithelial and smooth muscle ingrowth at the ends as well as neoangiogenesis on histologic exam (45).

A new technology developed in Japan called bio-3 D printing is under investigation as well. This method is scaffold-free and consists of various cell types (dermal fibroblasts, esophageal smooth muscle cells, bm-MSCs, umbilical vein endothelial cells) prepared into multicellular spheroids and then bio-3 D printed into, for example, esophageal-like tubes. One group utilized this technology and matured these tubes in a bioreactor for 4 weeks, then transplanted them into rats as an interposition graft from the stomach to the distal esophagus using a silicone stent for support. All rats survived to harvest at 30 days without major complication, with epithelium and smooth muscle cells present in all specimen. Orthotopic esophageal replacement did not work in this model due to aspiration pneumonia in the animals (46).

3D-printing applications to esophageal reconstruction are in their infancy of development, but should not be discounted. Printed PCL scaffolds already are demonstrating success as small patches. Full thickness circumferential grafts of larger diameter with reinforcement may not have the same stenosis problem that rat esophagus (2-3 mm diameter) did in the 2018 Chung study, although materially creating larger diameter and thicker grafts has not yet been feasible. Additionally, 3D-printed interposition grafts have not yet demonstrated peristaltic activity which has led to complications such as aspiration and obstruction in the experimented animals. Other studies of PCL grafts have established that MSC cell-seeding can help to speed stratified cell ingrowth and development, potentially resulting in more functional layers of neoesophagus; thus the combination of biomaterial 3D-printing advances with cell-seeding advances may be the key to customizable implantable neoesophagi.

\section{Summary of tissue engineering}

The immense diversity of materials and adjuncts to these is apparent in this review. Comparative studies of different cell-seeded and unseeded materials seem to suggest that mesenchymal stem cell or ADSC seeding in general leads to better cell ingrowth with mucosal and smooth muscle layers in the neo-esophageal tissue than in unseeded materials. What material is ideally used as a scaffold, and whether the construct may be amenable to a customizable 3D-printing technique is somewhat more unclear. Both absorbable synthetic polymers and decellularized matrices with cellseeding have shown similar promise in early animal models. Patches for small defects require less scaffolding strength as they do not necessarily need to sustain vast radial pressure nor generate contractions to provide for a functionally acceptable outcome. Thus, early human experimentation with tissue engineered grafts for small areas is the first step and these trials are ongoing as mentioned above.

Another consideration is the use of internal support for circumferential grafts as they heal. Temporary silicone stents that may be sutured in place and removable self-expanding stents have both been used in animal models to support scaffolds as they develop cell-ingrowth and strength, and can be utilized in humans as well. More work must be done in large animal models to mimic the physical stressors of the human esophagus to determine which combination of these materials and adjuncts will provide enough strength to avoid graft leak, diverticulae, and disruption during the healing process.

\section{Esophageal replacement and reconstruction}

Since the early days of esophageal resection a century and a half ago, few pioneers described multiple autologous tissue and organs for esophageal replacement or reconstruction.

Unfortunately, as the esophagus traverses 3 different body compartments, it functional complexity and its unique vascular structural anatomy, there is no method of esophageal replacement or esophageal substitute that is universally accepted and preferred.

While replacement of the esophagus with stomach, jejunum or colon is well established and further 
advancement in transplant medicine in the past half a century proved successful in many other organs, there has been no advancement in esophageal transplantation.

In the following section we will describe less frequent autologous and non-autologous esophageal replacement methods.

\section{Skin and fascia lata flaps for replacement of the esophagus}

Autologous replacement of the cervical esophagus with skin flap was first described by Mikulicz in 1886 (47). During the next century, other investigators described multiple methods using different skin flaps, mostly to the cervical or high thoracic esophagus, when visceral esophageal replacement using stomach or bowel failed or did not suffice. As a result of extensive morbidity, the need for multiple surgeries, high number of fistulas and skin irritation, the trend has been away from using skin flap based tubes. When a portion of a visceral segment is lost as a result of inadequate blood supply or when additional length of conduit is needed, pedicled skin flaps may be considered as a mean of salvage for reconstruction, though in practice these are scarcely used due to the above complications.

Fascia lata transfer was first used by Neuhoff and Ziegler in 1922 for esophageal replacement in dogs (48). Robe and Bateman later reconstructed the pharynx with tantalum wire mesh covered by fascia lata in 1949 (49). Others have tried to use Fascia lata with other non-viceral replacement methods to promote granulation to bridge gaps across esophageal segmental resections, however early failure and stenosis were common. As none of these substitutes have been satisfactory to heal the tissue or maintain patency, and other visceral substitutes have become more successful, and the use of fascial flaps has been abandoned.

\section{Aorta for replacement of the esophagus}

Allogenic aorta has been used in animal models for esophageal replacement. Fresh and/ or cryopreserved allogenic aorta has shown promising results in transformation into tracheal or esophageal tissue in vitro (50-52). Aortic graft preservation without rejection despite absence of immunotherapy has been also shown promising results in vitro and in a few animal models. Tessier used allogenic thoracic aorta harvested from rabbit donors for segmental replacement of the esophagus. The authors used a wrapping protocol to create an aortic tube graft which they modified a few times during their study. Unfortunately, their results were disappointing with dismal survival. Most of the recipients died during the $1^{\text {st }}$ week post-transplant from hypo-motility, or severe graft necrosis. The authors concluded that larger animal models may have better success as self-expanding stents might be used in them to protect the anastomoses, maintain luminal patency and protect the graft from contamination (53).

Gaujoux has used aortic allografts interposed in segmental resections of the cervical esophagus in a study in 18 piglets. The anastomoses were protected by a selfexpanding esophageal stent and no immunosuppression was given. Endoscopic surveillance was done at 1, 3, 6, 12 months post-surgery. The authors left the stent in for at least 6 months to avoid stenosis. After 12 months, the majority of the piglets showed gradual graft contraction, with adequate patency that allowed normal feeding and weight gain. Islets of smooth muscle organized as fascicules were identified as well. This successful study on piglets showed that the use of esophageal stents to protect the replaced esophageal segments by aortic allograft allows the restitution of patent esophageal lumen and nutritional autonomy without immunosuppressive therapy (54).

\section{Tracheal replacement of the esophagus}

Abbasidezfouli successfully replaced $8 \mathrm{~cm}$ of cervical esophagus by a $4-\mathrm{cm}$ segment of adjacent trachea in mongrel dogs. No post-operative mortality was noted and the dogs started on liquid diet after 48 hours and on regular diet on post-operative day 7. Two-month follow-up showed no stenosis or other complications. The authors reported histological changes in the replaced tracheal segments such as transition of the columnar mucosa to squamous mucosa, atrophy or disappearance of cartilaginous rings and inflammation of sub-mucosal glands. The authors hypothesized that the fibro-areolar tissue left intact between the esophagus and trachea contributed to the robust blood supply and survival of the graft. The successful replacement of an esophageal segment with half-sized tracheal segment might be feasible in humans where longer tracheal resections are limited (55).

\section{Complete esophageal transplantation}

Solid organ transplantation has evolved significantly 
in the past half century due to improvement in immunosuppression and continued refinements in surgical techniques. The need for complete esophageal replacement following corrosive esophageal injuries, long strictures, complex esophageal atresia, severe foregut dysfunction, lack of other viable autologous conduits and esophageal neoplasm, although rare, might be indicated in highly selected cases.

\section{Esophageal transplantation in rats}

Uygun et al. studied 14 male Sprague-Dawley rats who underwent total esophageal transplantation without vascular anastomoses. The authors created ostomies with the proximal and distal parts of the transplanted esophagus and divided the rat cohort into immunosuppressive treated and immunosuppressive untreated groups. 10 days post transplantation, all rats survived. There was no evidence of major complication in both groups and all rats retained preserved esophageal tissue. Inflammation and muscular atrophy were lower in the immunosuppressed group whereas vascularity was higher in that group. The authors concluded that total esophageal transplantation is feasible with reasonable outcomes with or without immunosuppression (56).

\section{Esophageal transplantation in humans}

Vakili et al., reported a case of donor esophagus transplantation as part of multi-visceral graft transplantation for restoration of GI continuity in a 9 years old female with an inflammatory myofibroblastic tumor. Following en bloc resection of the patient's visceral organs (Liver, stomach, duodenum, pancreas, small bowel, spleen, right and transverse colon), a donor's Multivisceral organ complex (including distal esophagus, stomach, liver, pancreas, duodenum, small bowel and spleen) were transplanted. Transhiatal end-to-end esophagoesophagostomy at the level of the inferior pulmonary vein was done. One point nine years post operatively the patient was doing well, tolerating oral intake with no reflux or dysphagia and endoscopy showed a widely patent esophageal anastomosis (57).

To date, there are no reported human studies exploring esophageal transplantation. One of the authors of this manuscript is conducting cadaveric feasibility studies, exploring different aspects of human esophageal transplantation. These include different possibilities of accessing the abundant blood supply in the thorax and the multiple compartments available for donor esophagus placement in the human thorax and mediastinum. Coupled with experience in foregut surgery and vascular microsurgery, these cadaveric feasibility studies have had early promising results and are ready for larger animal studies [Unpublished data].

\section{Conclusion}

Over the past 20 years, experimentation with tissueengineered esophageal repair and replacement has drastically advanced from purely in-vitro studies to viable animal models with long-term survival and now is reaching early human experimentation. What has been brought to light in both esophageal and other tissue engineering fields is that the scaffold alone seems to not be enough to support appropriate tissue in-growth. Stemcell and epithelial cell applications have led to much better functional and histological outcomes than various graft materials alone. We have yet to determine the best extracellular (or synthetic, or combination) matrix and the best source of cells to seed it and stimulate ingrowth of the highly complex layered structure of the native esophagus. Significant further work in this field will be necessary before human application of long segment grafts can be attempted, though for smaller patch applications we have already seen early successes.

Though farther behind in experimentation than tissueengineered grafts, esophageal transplantation remains a burgeoning field with little data but vast potential. Whole organ transplantation is the treatment of choice for total end-organ dysfunction in liver, kidney, pancreas and small bowel patients, and likewise may one day be the best option for esophageal replacement in select cases. This is especially true in those with total esophageal or long-segment disease where tissue-engineered grafts have not shown as much promise as in shorter-segment grafts. We look forward to the results of upcoming experimentation in animal models of esophageal allotransplantation.

\section{Acknowledgments}

Funding: None.

\section{Footnote}

Provenance and Peer Review: This article was commissioned 
by the editorial office, Annals of Translational Medicine for the series "Innovations and Updates in Esophageal Surgery". The article has undergone external peer review

Reporting Checklist: The authors have completed the Narrative Review reporting checklist. Available at http://dx.doi.org/10.21037/atm-20-3906

Conflicts of Interest: Both authors have completed the ICMJE uniform disclosure form (available at http://dx.doi. org/10.21037/atm-20-3906). The series "Innovations and Updates in Esophageal Surgery" was commissioned by the editorial office without any funding or sponsorship. OW served as the unpaid Guest Editor of the series and serves as an unpaid editorial board member of Annals of Translational Medicine from Oct 2019 to Sep 2021. The authors have no other conflicts of interest to declare.

Ethical Statement: The authors are accountable for all aspects of the work in ensuring that questions related to the accuracy or integrity of any part of the work are appropriately investigated and resolved.

Open Access Statement: This is an Open Access article distributed in accordance with the Creative Commons Attribution-NonCommercial-NoDerivs 4.0 International License (CC BY-NC-ND 4.0), which permits the noncommercial replication and distribution of the article with the strict proviso that no changes or edits are made and the original work is properly cited (including links to both the formal publication through the relevant DOI and the license). See: https://creativecommons.org/licenses/by-nc-nd/4.0/.

\section{References}

1. Kunisaki SM, Coran AG. Esophageal replacement. Semin Pediatr Surg 2017;26:105-15.

2. Gallo G, Zwaveling S, Groen H, et al. Long-gap esophageal atresia: a meta-analysis of jejunal interposition, colon interposition, and gastric pull-up. Eur J Pediatr Surg 2012;22:420-5.

3. Spitz L. Esophageal Replacement: overcoming the need. J Pediatr Surg 2014;49:849-52.

4. Totonelli G, Maghsoudlou P, Fishman JM, et al. Esophageal tissue engineering:a new approach for esophageal replacement. World J Gastroenterol 2012;18:6900-7.

5. Poghosyan T, Catry J, Luong-Nguyen M, et al. Esophageal tissue engineering: Current status and perspectives. J Visc Surg 2016;153:21-9.

6. Maghsoudlou P, Eaton S, De Coppi P. Tissue Engineering of the esophagus. Semin Pediatr Surg 2014;23:127-34.

7. Freud E, Efrati I, Kidron D, et al. Comparative experimental study of esophageal wall regeneration after prosthetic replacement. J Biomed Mater Res 1999;45:84-91.

8. Lynen Jansen P, Klinge U, Anurov M, et al. Surgical Mesh as a scaffold for tissue regeneration in the esophagus. Eur Surg Res 2004;36:104-11.

9. Takimoto $Y$, Nakamura T, Yamamoto $Y$, et al. The experimental prelacement of a cervical esophageal segment with and artifical prosthesis with the use of collagen matrix and a silicone stent. J Thorac Cardiovasc Surg 1998;116:98-106.

10. Yamamoto Y, Nakamura T, Shimizu Y, et al. Intrathoracic esophageal replacement in the dog with the use of an artificial esophagus composed of a collagen sponge with a double-layered silicone tube. J Thorac Cardiovasc Surg 1999;118:276-86.

11. Yamamoto Y, Nakamura T, Shimizu Y, et al. Intrathoracic esophageal replacement with a collagen sponge--silicone double layer tube: evaluation of omental-pedicle wrapping and prolonged placement of an inner stent. ASAIO J 2000;46:734-9.

12. Beckstead BL, Pan S, Bhrany AD, et al. Esophageal epithelial cell interaction with synthetic and natural scaffolds for tissue engineering. Biomaterials 2005;26:6217-28.

13. Zhu Y, Chan-Park MB. Density quantification of collagen grafted on biodegradable polyester: its application to esophageal smooth muscle cell. Anal Biochem 2007;363:119-27.

14. BaoLin G, Ma PX. Synthetic Biodegradable functional polymers for tissue engineering: a breif review. Sci China Chem 2014;57:490-500.

15. Nakase $Y$, Nakamura T, Kin S, et al. Intrathoracic esophageal replacement by in situ tissue-engineered esophagus. J Thorac Cardiovasc Surg 2008;136:850-9.

16. Orlando G, Domínguez-Bendala J, Shupe T, et al. Cell and organ bioengineering technology as applied to gastrointestinal diseases. Gut 2013;62:774-86. Corrected in Gut 2014;63:229.

17. Diemer P, Markoew S, Le DQ, et al. Poly-e-caprolactone mesh as a scaffold for in vivo tissue engineering in rabbit esophagus. Dis Esophagus 2015;28:240-5.

18. Maghsoudlou P, Georgiades F, Tyraskis A, et al. 
Preservation of micro-architecture and angiogenic potential in a pulmonary acellular matrix obtained using intermittent intra-tracheal flow of detergent enzymatic treatment. Biomaterials 2013;34:6638-48.

19. Voytik-Harbin SL, Brightman AO, Kraine MR, et al. Identification of extractable growth factors from small intestinal submucosa. J Cell Biochem 1997;67:478-91.

20. Moser PT, Gerli M, Diercks GR, et al. Creation of laryngeal grafts from primary human cells and decellularized laryngeal scaffolds. Tissue Eng Part A 2020;26:543-555.

21. Willemse J, Verstegen MMA, Vermeulen A, et al. Fast, robust and effective decellularization of while human livers using mild detergents and pressure controlled perfusion. Mater Sci Eng C Mater Biol Appl 2020;108:110200.

22. Sabbagh MD, Roh SG, Liu J, et al. A quick and reliable method to decellularize a gracilis flap: a crucial step toward building a muscle. Ann Plast Surg 2019;83:709-715.

23. Arakelian L, Caille C, Faivre L, et al. A clinical-grade acellular matrix for esophageal replacement. J Tissue Eng Regen Med 2019;13:2191-203.

24. Luc G, Charles G, Gronnier C, et al. Decellularized and matured esophageal scaffold for circumferential esophagus replacement: Proof of concept in a pig model. Biomaterials 2018;175:1-18.

25. Isch JA, Engum SA, Ruble CA, et al. Patch Esophagoplasty using Alloderm as a tissue scaffold. J Pediatr Surg 2001;36:266-8.

26. Doede T, Bondartschuk M, Joerck C, et al. Unsuccessful alloplastic esophageal replacement with porcine small intestinal submucosa. Artif Organs 2009;33:328-33.

27. Badylak S, Meurling S, Chen M, et al. Resorbable bioscaffold for esophageal repair in a dog model. J Pediatr Surg 2000;35:1097-103.

28. Fan MR, Gong M, Da LC, et al. Tissue engineered esophagus scaffold constructed with porcine small intestinal submucosal and synthetic polymers. Biomed Mater 2014;9:015012.

29. Syed O, Kim JH, Keskin-Erdogan Z, et al. SIS/aligned fibre scaffold designed to meet layered oesophageal tissue complexity and properties. Acta Biomater 2019;99:181-95.

30. Algarrahi K, Franck D, Ghezzi CE, et al. Acellular bi-layer silk fibroin scaffolds support functional tissue regeneration in a rat model on onlay esophagoplasty. Biomaterials 2015;53:149-59.

31. Algarrahi K, Franck D, Cristofaro V, et al. Bi-layer silk fibroin grafts support functional tissue regeneration in a porcine model of onlay esophagoplasty. J Tissue Eng
Regen Med 2018;12:e894-e904.

32. Chung EJ, Ju HW, Park HJ, et al. Three-layered scaffolds for artificial esophagus using poly( $\varepsilon$-caprolactone) nanofibers and silk fibroin: an experimental study in a rat model. J Biomed Mater Res A 2015;103:2057-65.

33. Jensen T, Wanczyk H, Sharma I, et al. Polyurethane scaffolds seeded with autologous cells can regenerate long esophageal gaps: an esophageal atreasia treatment model. J Pediatr Surg 2019;54:1744-54.

34. Ohki T, Yamato M, Murakami D, et al. Treatment of oesophageal ulcerations using endoscopic transplantation of tissue-engineered autologous oral mucosal epitehlial cell sheets in a canine model. Gut 2006;55:1704-10.

35. Wei RQ, Tan B, Tan MY, et al. Grafts of porcine small intestinal submucosa with cultured autologous oral mucosal epithelial cells for esophageal repair in a canine model. Exp Biol Med (Maywood) 2009;234:453-61.

36. Tan B, Wei RQ, Tan MY, et al. Tissue engineered esophagus by mesenchymal stem cell seeding for esophageal repari in a canine model. J Surg Res 2013;182:40-8.

37. Catry J, Luong-Nguyen M, Arakelian L, et al. Circumferential Esophageal Replacement by a Tissueengineered substitute using mesenchymal stem cells: An experimental study in mini pigs. Cell Transplant 2017;26:1831-1839.

38. La Francesca S, Aho JM, Barron MR, et al. Long-term regeneration and remodeling of the pig esophagus after circumferential resection using a retrievable synthetic scaffold carrying autologous cells. Sci Rep 2018;8:4123.

39. Badylak SF, Hoppo T, Nieponice A, et al. Esophageal preservation in Five Male Patients after endoscopic innerlayer circumferential resection in the setting of superficial cancer: a regerative medicine approach with a biologic scaffold. Tissue Eng Part A 2011;17:1643-50.

40. Ohki T, Yamato M, Ota M, et al. Prevention of esophageal stricture after endoscopic submucosal dissection using tissue-engineered cell sheets. Gastroenterology 2012;143:582-588.e2.

41. Nieponice A, Ciotola FF, Nachman F, et al. Path Esohpagoplasty: esophageal reconstruction using biologic scaffolds. Ann Thorac Surg 2014;97:283-8.

42. Dua KS, Hogan WJ, Aadam AA, et al. In-vivo oesophageal regeneration in a human being by use of a non-biological scaffold and extracellular matrix. Lancet 2016;388:55-61.

43. Park SY, Choi JW, Park JK, et al. Tissue-engineered artificial oesophagus patch using three-dimensionally printed polycaprolactone with mesenchymal stem cells: 
a preliminary report. Interact Cardiovasc Thorac Surg 2016;22:712-7.

44. Park H, Kim IG, Wu Y, et al. Experimental investigation of esophageal reconstruction with electrospun polyurethane nanofiber and 3D printing polycaprolactone scaffolds using a rat model. Head Neck 2021;43:833-48.

45. Chung EJ, Ju HW, Yeon YK, et al. Development of an omentum-cultured oesophageal scaffold reinforced by a 3D-printed ring: feasibility of an in vivo bioreactor. Artif Cells Nanomed Biotechnol 2018;46:885-95.

46. Takeoka Y, Matsumoto K, Taniguchi D, et al. Regeneration of esophagus using a scaffold-free biomimetic structure created with bio-three-dimensional printing. PLoS One 2019; 14:e0211339.

47. May IA, Samson PC. Esophagel reconstuction and replacements. Ann Thorac Surg 1969;7:249-77.

48. Neuhoff HaZ, JM. Experimental reconstruction of the esophagus by granulation tubes. Surgery, Gynecology, and Obstetrics. 1922:767.

49. Rob CG, Bateman GH. Reconstruction of the trachea and cervical oesophagus; preliminary report. Br J Surg 1949;37:202-5, illust.

50. Martinod E, Seguin A, Holder-Espinasse M, et al.

Cite this article as: Model L, Wiesel O. A narrative review of esophageal tissue engineering and replacement: where are we? Ann Transl Med 2021;9(10):910. doi: 10.21037/atm-20-3906
Tracheal regeneration following tracheal replacement with an allogenic aorta. Ann Thorac Surg 2005;79:942-8.

51. Jaillard S, Holder-Espinasse M, Hubert T, et al. Tracheal replacement by allogenic aorta in the pig. Chest 2006;130:1397-404.

52. Seguin A, Radu D, Holder-Espinasse M, et al. Tracheal Replacement With Cryopreserved, Decellularized, or Glutaraldehyde-Treated Aortic Allografts. Ann Thorac Surg 2009;87:861-7.

53. Tessier W, Mariette C, Copin MC, et al. Replacement of the esophagus with fascial flap-wrapped allogenic aorta. J Surg Res 2015;193:176-83.

54. Gaujoux S, Le Balleur Y, Bruneval P, et al. Esophgaeal replacement by allogenic aorta in a porcine model. Surgery 2010;148:39-47.

55. Abbasidezfouli A, Ansari D, Sheikhy K, Abarkar M, et al. Experimental replacement of esophagus with a short segment of trachea. J Surg Res 2016;201:94-8.

56. Uygun I, Okur MH, Aydogdu B, et al. Esophageal Transplantation in the rat. J Pediatr Surg 2013;48:1670-5.

57. Vakili K, Kim HB. Partial Esophageal Transplantation is Possible as Part of a Multivisceral Graft. Am J Transplant 2014;14:720-3. 